TẠP CHÍ KHOA HỌC ĐÄI HỌC TÂN TRÀO
ISSN: 2354 - 1431

\title{
BIẾN ĐỔI TRONG TÍN NGƯỠNG CỦA CỦ DÂN ĐẢO HÒN TRE, THÀNH PHỐ NHA TRANG
}

\author{
Truơng Thị Quốc Ánh ${ }^{{ }^{*}}$ \\ ${ }^{1}$ Khoa Du lịch - Truòng Đại học Khánh Hòa \\ *Email: truongthiquocanh@ukh.edu.vn
}

\section{Thông tin bài viết}

Ngày nhận bài:

$22 / 6 / 2020$

Ngày duyệt đăng:

20/9/2020

Từ khóa:

Biến đổi tín ngương, biến

đổi văn hóa, tín nguõng

\section{Tóm tắt}

Bài viết đề cập đến thực trạng tín ngưỡng của cư dân đảo Hòn Tre với những biến đổi của nó trong bối cảnh hiện nay. Trên cơ sở đó chúng tôi sẽ làm rõ những thay đổi trong niềm tin tín ngưỡng; thực hành tín ngưỡng; đối tượng, cơ sở thờ tự và lễ vật thờ cúng. Phần cuối báo cáo là một số kết luận về quá trình biến đổi tín ngưỡng của cư dân đảo Hòn Tre, đồng thời chỉ ra sự tồn tại song hành hai xu hướng vận động của tín ngưỡng, đó là gìn giữ tín ngưỡng theo nếp cũ (truyền thống) và biến đổi cho phù hợp với hoàn cảnh mới.

\section{PHẦN MỞ ĐẦU}

Biến đổi là một quy luật tất yếu trong sự vận động không ngừng của lịch sử, chi phối mọi lĩnh vực của đời sống con người, trong đó có văn hóa. Tùy vào nhân tố tác động cũng như "bản lĩnh tự thân", các thành tố của văn hóa biến đổi khác nhau về tốc độ, quy mô, phương thức, trạng thái. Sự biến đổi đó biểu hiện xu thế hay các trạng hướng vận động mới của văn hóa.

Là một trong 19 đảo thuộc vịnh Nha Trang, Hòn Tre $^{1}$ là đảo lớn nhất với diện tích 3.250 ha. Đảo nằm trong vịnh kín gió, đáy biển nhiều cát, nước trong, kết hợp với các dòng hải lưu nóng lạnh thích hợp cho sự phát triển của các loài thực vật, sinh vật phù du... Do vậy, Hòn Tre là địa điểm thích hợp cho hoạt động đánh bắt và nuôi trồng thủy sản. Cư dân sinh sống chủ yếu là ngư dân, thuộc các khóm đảo: Bãi trũ Vũng Me, Vũng Ngán, Đầm Bấy, Bích Đầm.

Cuộc sống mưu sinh bằng nghề biển đầy hiểm nguy, bất trắc nên sự ra đời của tín ngưỡng như một nhu cầu lớn lao, là chỗ dựa về mặt tinh thần không

\footnotetext{
${ }^{1}$ Nhiều cư dân địa phương cho rằng tên đúng của đảo phải là Hòn Che bởi đảo có vị trí án ngữ dông bão, che chắn cho thành phố Nha Trang.
}

thể thiếu, giúp cư dân chống chọi với bao tai ách, biến động của tự nhiên và xã hội. Chính vì vậy mà hệ thống tín ngưỡng của cư dân Hòn Tre rất đa dạng: tín ngưỡng thờ thần Thành Hoàng và Tiền hiền, tín ngưỡng thờ cá Ông, tín ngưỡng thờ Mẫu và Nữ thần biển, tín ngưỡng cúng cô hồn biển... Chúng thể hiện niềm tin của cư dân vào lực lượng siêu nhiên, độ trì cứu giúp họ tránh tai họa và cầu mong thu hoạch nhiều sản phẩm của biển.

Ngày nay, bối cảnh kinh tế xã hội đã tác động lớn đến sự thay đổi ở Hòn Tre, một trong những biểu hiện rõ nét nhất là quá trình chuyển đổi từ ngư nghiệp truyền thống sang phát triển một số ngành nghề kinh tế khác, trong đó điển hình là kinh tế du lịch. Như một quy luật tất yếu, những đổi thay về môi trường, điều kiện sống là tác nhân gây nên những biến đổi về văn hóa tinh thần. Những thực hành sinh hoạt văn hóa, tín ngưỡng cổ truyền của cư dân vùng đảo được duy trì, diễn ra trong một bối cảnh phức tạp như vậy không thể không có các biến đổi khác trước. Bài viết này đề cập đến thực trạng tín ngưỡng của cư dân đảo Hòn Tre với những biến đổi của nó trong bối cảnh hiện nay. 


\section{NỘI DUNG}

\subsection{Thay đổi trong niềm tin tín ngưỡng}

Sự kết hợp giữa yếu tố nông nghiệp trong cội nguồn và ngư nghiệp nơi vùng đất mới trong sinh hoạt và lao động sản xuất đã dẫn đến sự đa dạng trong tâm thức thờ thần của người Việt trên đảo Hòn Tre. Niềm tin là yếu tố cốt lõi để tạo nên tâm thức tín ngưỡng và được biểu hiện qua các hành vi thờ cúng.

Đối với cư dân Hòn Tre, niềm tin tín ngưỡng được thể hiện qua việc thờ cúng cá Voi, thờ thần Thành Hoàng, thờ Tiền hiền, Hậu hiền, thờ Nữ thần/Mẫu thần, cúng Cô hồn/Cô bác. Ngoài ra, còn có một số tục thờ khác như: thần Giám, thần cai quản, tổ nghề... Niềm tin này được hình thành từ nhiều nguyên nhân. Trước hết, xuất phát từ quan niệm "có thờ có thiêng, có kiêng có lành”. Nhất là đối với cộng đồng cư dân sinh sống bằng nghề biển, nhiều rủi ro lắm hiểm nguy thì quan niệm này lại càng ăn sâu vào tâm thức của họ. Bên cạnh đó, khi mới đến định cư ở vùng đất mới, người Việt đã lập nên các bàn thờ Thành Hoàng, Tiền hiền... trước là để nhớ về cội nguồn, tưởng nhớ công ơn, sau là để cầu xin sự phù hộ độ trì để được yên ổn, no ấm. Mặc khác, người miền biển luôn mang trong mình những câu chuyện, những giai thoại, những sự tích ly kỳ, tâm linh huyền bí, đó cũng chính là cơ sở để người dân đặt niềm tin với sự linh thiêng của các vị thần.
Ngư dân Phạm Phú ${ }^{2}$ kể, cách đây gần 10 năm, tàu ông đang đánh bắt trên vùng biển Hoàng Sa thì bỗng nhiên gặp bão lớn. Tàu chìm, toàn bộ ngư dân đi thuyền bị sóng nhồi kiệt sức và buông xuôi sau đó. Còn ông, nhờ có sức khỏe và may mắn bám vào cây khô trôi nổi trên biển nên trụ lại lâu hơn. Nhưng nhiều giờ bị sóng đánh, ông cũng đuối sức. Giữa lúc cái chết cận kề, ngư dân van vái và được Ông Nam Hải đến cứu giúp. Đến bây giờ, ông vẫn còn nguyên cảm giác mừng rỡ khi thân mình đang chìm dưới nước bỗng dưng được Ông đẩy lên và đưa nhanh vào bờ [Nguồn: kết quả phỏng vấn của tác giả].

Để có thông tin và số liệu cụ thể phục vụ cho việc phân tích biến đổi tín ngưỡng tại cộng đồng cư dân Hòn Tre, chúng tôi đã tiến hành phát 210 phiếu hỏi ở 3 khóm đảo: Bích Đầm, Vũng Ngán và Đầm Bấy, mỗi khóm đảo 70 phiếu. Trong đó có 120 nam, 90 nữ; 70 người là ngư dân, 50 người buôn bán, dịch vụ, 20 người là cán bộ, công nhân viên chức và 70 người thuộc thành phần khác (sinh viên, thất nghiệp...).

Kết quả khảo sát cho thấy, cư dân đảo Hòn Tre vẫn đặt niềm tin vào các vị thần của làng như thần Nam Hải, Bà Thiên Y Ana, Thành hoàng, Lệnh chúa thủy, Cô bác... ở mức độ không giống nhau. ${ }^{2}$ Cộng tác viên Phạm Phú cư trú tại khóm đảo Bích Đầm
đã đồng ý cho tác giả đề cập họ tên của mình trong bài viết.

Biểu đồ 1: Niềm tin vào tín ngưỡng của cư dân tại 3 điểm nghiên cứu

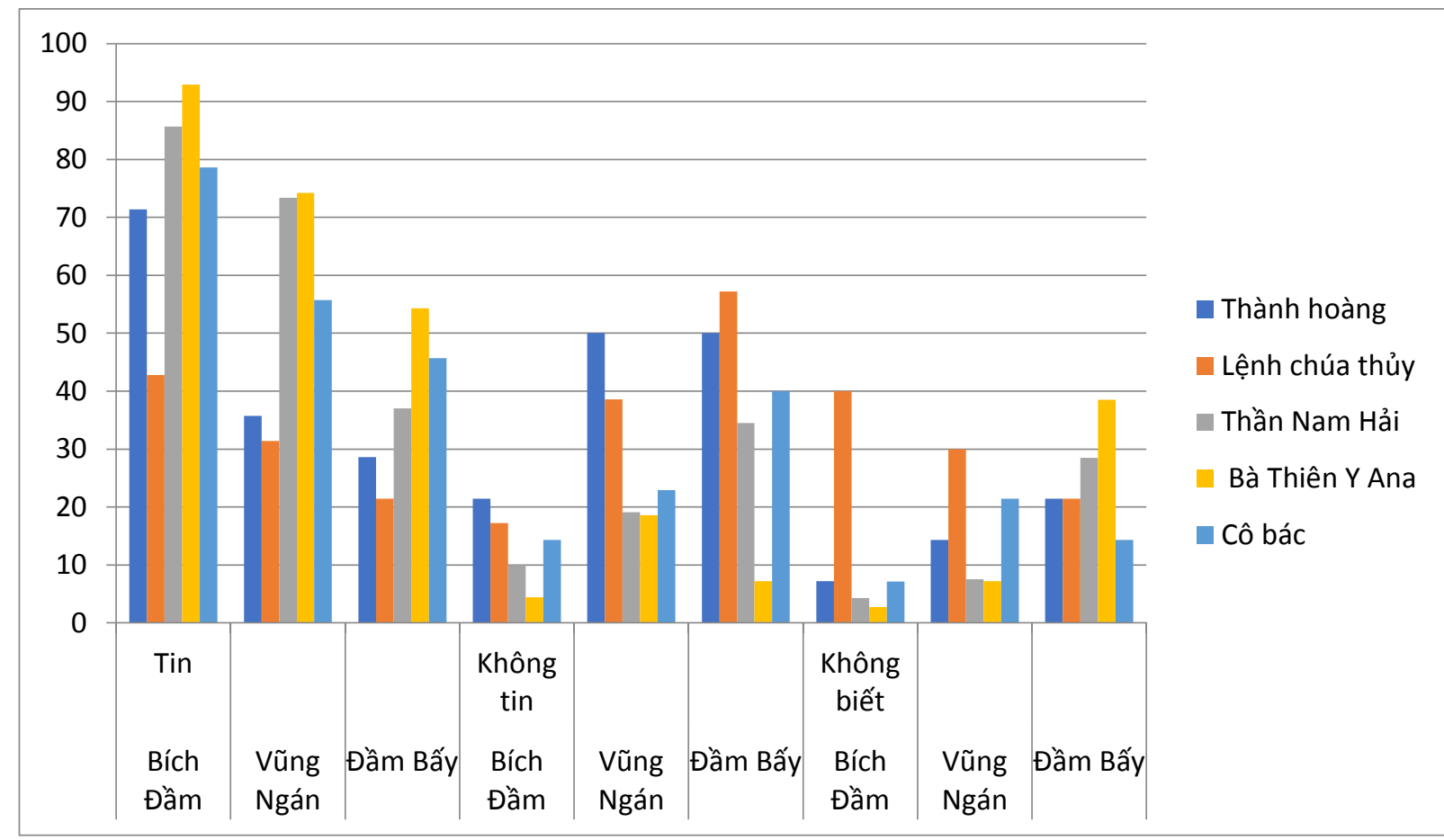


Ở biểu đồ 1 , có thể thấy niềm tin của cư dân Hòn Tre dành cho các vị thần không có sự đồng nhất. Ở Đầm Bấy, không quá 50\% số người được hỏi tin vào sự linh thiêng của thần Thành Hoàng, Lệnh chúa thủy, thần Nam Hải và Cô bác, đa số trả lời không tin hoặc không biết gì về các vị thần đó. Trong khi đó ở Vũng Ngán, niềm tin của người dân lại chủ yếu tập trung vào các vị thần gắn với nghề biển như: thần Nam Hải (73.4\%), Bà Thiên Y Ana (74.2\%), Cô bác $(55.7 \%)$. Không chỉ các vị thần gắn với nghề biển mới được đa số cư dân tin như ở Vũng Ngán, niềm tin ở cư dân Bích Đầm trải đều ở cả các thần, thậm chí mức độ còn đậm đặc hơn với $71.4 \%$ tin vào thần
Thành Hoàng, 85.7\% tin vào thần Nam Hải, 92.9\% tin vào Thiên Y Ana và $78.6 \%$ tin vào Cô bác.

Nhìn chung có một bộ phận cư dân đảo Hòn Tre hiện nay không còn tin vào các vị thần tín ngưỡng của làng, trong khi trước đây được cả cộng đồng dân biển tin theo, biểu hiện rõ nhất là Đầm Bấy.

\subsection{Thay đổi trong thực hành tín ngưỡng}

Với niềm tin tín ngưỡng sâu sắc, trong truyền thống cư dân Hòn Tre thực hành tín ngưỡng thường xuyên, không chỉ các dịp lễ hay lễ hội mà còn cả trước mỗi lần đi biển và sau khi đi biển về.

Khi đặt ra các câu hỏi có liên quan đến vấn đề thực hành tín ngưỡng ở cư dân đảo Hòn Tre hiện nay, chúng tôi thu được kết quả như sau:

Biểu đồ 2: Tần suất đến các cơ sở thờ tự của 3 làng

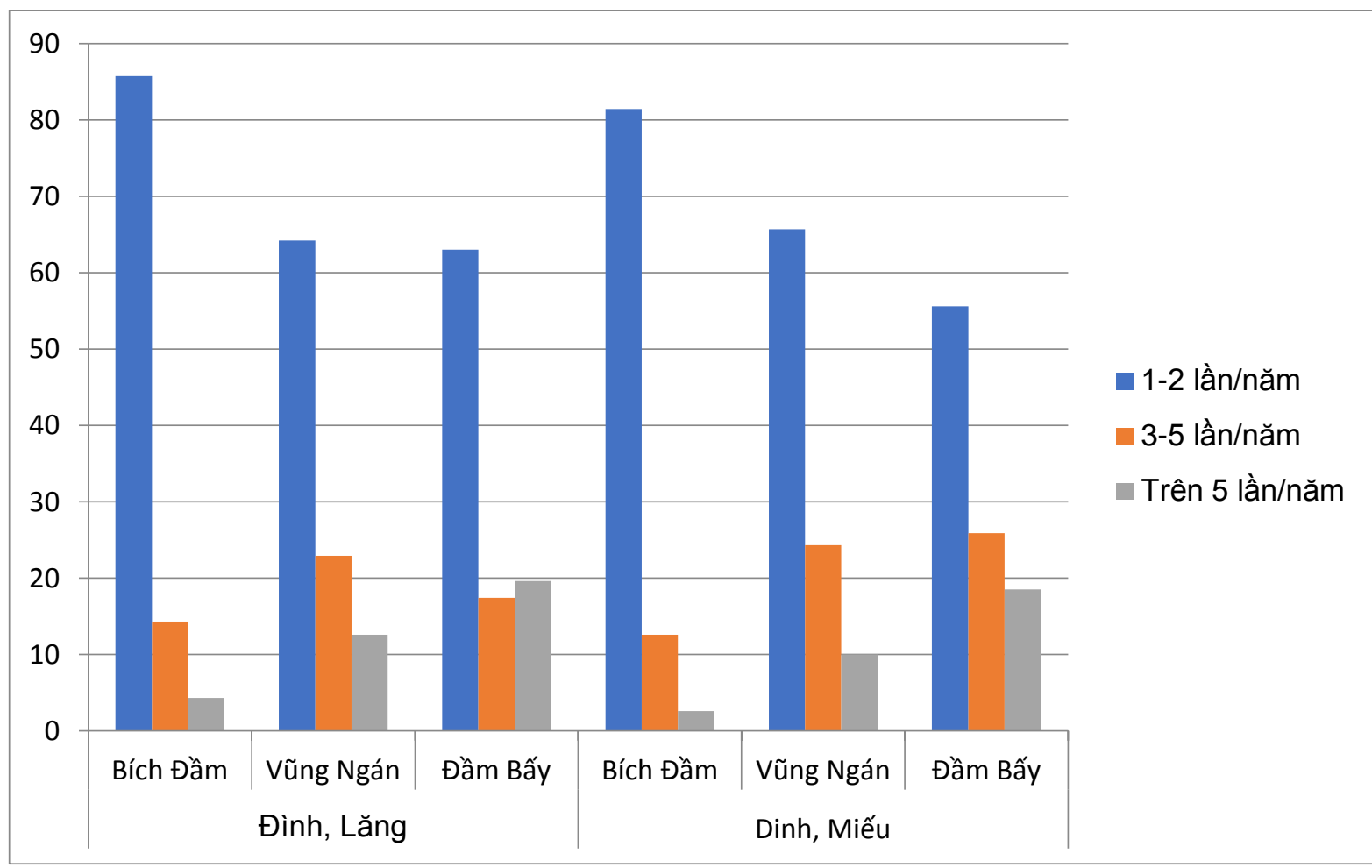

Kết quả khảo sát tần suất đến cơ sở thờ tự cho thấy, ở Đầm Bấy số người đến dinh, miếu ngày càng giảm. Số người đến đình, lăng có tăng nhưng không đáng kể. Còn ở Vũng Ngán và Bích Đầm dù là đình, lăng hay dinh, miếu số người đến có xu hướng tăng lên, chủ yếu là 1-2 lần/năm vào những dịp có lễ cúng lớn như lễ Cầu Ngư, lễ Vía Bà. Đồng thời số người đến đình, lăng cũng nhiều hơn so với dinh, miếu. Người dân cho biết, đình và lăng nằm ở giữa làng nên tiện cho việc đi lại, cúng bái, hơn nữa những
Nguồn: Xủ lý kết quả điều tra bảng hỏi của tác giả đối tượng được thờ ở đây gắn liền với cuộc sống lao động hằng ngày còn dinh, miếu nằm tương đối xa lại ít "thân thuộc". Bên cạnh đó, có một số nguyên nhân tương đồng trong ý kiến của cư dân ở 3 làng khi hỏi về sự thay đổi trong việc đến các cơ sở thờ tự tín ngưỡng, đó là: Đi nhiều hơn vì tham gia vào Ban khánh tiết của làng, có thời gian rảnh nhiều hơn do già rồi không đi làm nữa; còn đi ít hơn vì bận đi làm ngoài đất liền, không làm nghề biển nữa, bận chăm con. 
Bảng 1. Đóng góp của các hộ gia đình cho hoạt động thực hành tín ngưỡng

\begin{tabular}{|l|c|c|c|}
\hline & Đầm Bấy & Vũng Ngán & Bích Đầm \\
\hline Đóng góp & 51,4 & 85,7 & 94,3 \\
\hline Không đóng góp & 48,6 & 14,3 & 5,7 \\
\hline
\end{tabular}

Nguồn: Xủ lý kết quả điều tra bảng hỏi của tác giả

Đối với nội dung khảo sát đóng góp của các gia đình cho hoạt động tín ngưỡng tại đảo cho thấy hầu hết người dân ở làng Vũng Ngán và Bích Đầm đều tự nguyện ủng hộ với tỷ lệ lần lượt là $86 \%$ và $94,3 \%$. Trong khi đó ở Đầm Bấy số người không đóng góp lên đến 34 người (chiếm 48,6\%).

Như vậy, trên cơ sở sự thay đổi về niềm tin tín ngưỡng đã dẫn đến việc thực hành tín ngưỡng ở cư dân đảo Hòn Tre hiện nay cũng có chiều hướng suy giảm theo. Mặt khác, kết quả khảo sát cho thấy thực hành tín ngưỡng đã có sự khác biệt giữa các làng. So với Đầm Bấy nay chủ yếu sinh sống dựa vào các hoạt động du lịch, thì Vũng Ngán và Bích Đầm - nơi vẫn còn đa số cư dân theo nghề biển việc thực hành tín ngưỡng diễn ra thường xuyên và thu hút đông đảo người dân hơn.

Với tư cách là chủ thể tín ngưỡng truyền thống, sự suy giảm trong niềm tin và thực hành tín ngưỡng của cư dân đảo Hòn Tre sẽ ảnh hưởng đến sự duy trì, bảo tồn tín ngưỡng cộng đồng đã tồn tại lâu đời tại đây.

\subsection{Thay đổi trong đối tượng và cơ sở thờ tự}

Cùng với sự thay đổi trong niềm tin và thực hành tín ngưỡng, đối tượng thờ cúng của cư dân đảo Hòn Tre đã có sự thay đổi. Một số vị thần dần vắng bóng trong đời sống tinh thần người dân dù vẫn có cơ sở thờ tự. Là làng có nhiều đình, miếu thờ thần nhất trong ba làng khảo sát nhưng hiện nay Bích Đầm chỉ cúng lễ các thần Thành Hoàng, thần Nam Hải, Bà Thiên Y Ana, Tiền hiền, Cô bác. Các miếu còn lại như An Thanh miếu, Dinh ông Lớn, Dinh 4 vị thần cai quản hướng, miếu tổ nghề... hầu như để hoang. Nguyên nhân do các miếu này cách xa làng, không thuận tiện cho việc đi lại. Trường hợp An Thanh miếu trước đây là nơi người dân đến xin các bài thuốc chữa bệnh nhưng hiện nay cách điều trị này không còn phù hợp nên họ ít đến viếng thăm.

Về cơ sở thờ tự, hầu hết các đình, lăng, miếu trên đảo đã trải qua nhiều lần trùng tu hoặc xây mới đặc biệt trong khoảng thời gian từ năm 2010 trở lại đây nên ít nhiều đã mang những nét kiến trúc khác trước.

Lăng miếu Đầm Bấy xây lại vào năm 2012. Nếu trước đây, đình được xây dựng bằng gỗ, có lầu chiêng trống, bình phong thì nay được xây hoàn toàn bằng xi măng cốt thép, không mang kiến trúc quen thuộc của Đức Ngư Ông, chỉ còn nhà lăng cấu trúc 3 gian với diện tích vẻn vẹn 24 mét vuông, không có hàng rào bao quanh.

Lăng miếu Vũng Ngán, trước đây cổng lăng nằm ở phía Đông, hướng ra biển, nhưng theo quy hoạch, khu du lịch Vinpearland xây án ngữ trước lăng, cổng mới mở ra phía bên cạnh, hướng Bắc. Cổng cũ chỉ còn dấu tích bình phong xây nối thành tường rào của lăng.

Cách bài trí bên trong các cơ sở thờ tự là việc treo ảnh, bằng khen hoặc bảng khắc tên những người đã cúng tiền cho việc xây dựng, trùng tu như ở đình Bích Đầm.

\subsection{Thay đổi trong lễ vật thờ cúng}

Các lễ cúng truyền thống ở Hòn Tre vẫn được duy trì, bảo lưu nhiều yếu tố cổ truyền, tuy nhiên có sự gia giảm cho phù hợp với hoàn cảnh thực tại. $\mathrm{Xu}$ hướng chủ đạo hiện nay trong thực hiện các nghi lễ cúng tế là đơn giản hóa, thể hiện ở sự thu hẹp về thời gian, thu nhỏ quy mô tổ chức, bỏ bớt một số tiểu lễ cũng như không cầu kỳ, câu nệ trong lễ vật dâng thần. Do phạm vi bài viết có giới hạn nên chúng tôi chỉ xin đề cập đến những thay đổi trong lễ vật thờ cúng.

Trước hết, việc kiêng kỵ đối với những vật phẩm dâng thần trong các buổi lễ không còn nghiêm ngặt như trước. Tranh các hình nhân thế mạng dùng trong lễ tống ôn, trước do người trong làng vẽ nay mua ngoài chợ, không thể hiện đầy đủ ý nghĩa ban đầu. Hay như lốt Bà Thủy vẽ hình người phụ nữ nửa trên là người, nửa dưới là cá, xung quanh là sóng nước không như trước đây xung quanh là các lực lượng “trợ thủ” của Bà như con đẻn, con vích.

Sự thay đổi trong đồ dâng cúng theo hướng đơn giản, tiện dụng. Ở Bích Đầm, trong các lễ cúng trước đây, ở mỗi cơ sở thờ tự đều đặt một con gà giò để coi điềm cát hung cho làng trong năm, nhưng nay đã bỏ bởi nguồn kinh phí không cho phép. Đồ lễ có đầu heo, thịt heo luộc (năm nào làm lớn thì nguyên một con heo quay), hình vẽ người thế mạng, lốt cá voi, lốt bà Thủy, bà Mộc, bà Ngũ hành, 1 con cua, 4 con tôm, 4 quả trứng vịt. Thời gian gần đây, đồ lễ chỉ có đầu heo, thịt heo luộc, bánh chưng, bánh tráng, lốt bà Thủy. 
Sự tiện dụng còn được thể hiện ở việc mua sẵn hay đặt làm đối với lễ vật dâng thần. Năm 2015, sau 6 năm làng Vũng Ngán mới tổ chức lễ cầu ngư lớn nên đặt nấu 5 bàn với các món ăn mang tính chất tiệc như nộm, súp, lagu bánh mì, cá hấp, gà bó xôi...

Đặc điểm nói trên khiến cho thời gian cúng lễ thay đổi (như lễ tế Cô hồn thay vì tổ chức vào lúc tờ mờ sáng, khoảng 4 giờ sáng thì nay tổ chức vào lúc 6 giờ sáng, thậm chí muộn hơn), đồng thời cũng làm giảm những quy chuẩn trong việc lựa chọn lễ vật tế thần. Bởi thay vì tự đi chọn và mua như trước, hiện nay đặt làm nên dù đã yêu cầu người bán lựa chọn cẩn thận theo những tiêu chuẩn, song nhiều lúc vẫn không được như ý, nhưng phải đành chấp nhận.

\section{KẾT LUẦN}

Việc xây dựng cơ sở hạ tầng, phát triển kinh tế hướng biển, chuyển đổi nghề nghiệp... đã tác động mạnh mẽ đến khu vực đảo Hòn Tre, trước hết làm thay đổi không gian cư trú, tiếp sau là không gian sinh hoạt văn hóa, tín ngưỡng.

Sự biến đổi tín ngưỡng của cư dân đảo Hòn Tre phản ảnh trên nhiều phương diện, từ những yếu tố hữu thể đến những yếu tố vô hình. Mặt khác nó diễn ra với cường độ và quy mô không giống nhau ở các thành tố tín ngưỡng và ở các làng trên đảo. Đầu tiên, không gian gốc cấu thành tín ngưỡng bị thu hẹp bởi những dự án du lịch và sự chuyển dịch hay biến mất của một số cơ sở thờ tự tín ngưỡng. Cùng với đó là một số biến đổi khác diễn ra trong sinh hoạt tín ngưỡng như việc tận dụng tiến bộ khoa học vào hoạt động thờ cúng, hay không quá khắt khe đối với vật phẩm dâng cúng. Bên cạnh đó, niềm tin và thực hành tín ngưỡng cũng suy giảm.

Quá trình vận động của tín ngưỡng ở cư dân đảo Hòn Tre cho thấy có sự tồn tại song hành hai xu hướng vận động, đó là gìn giữ tín ngưỡng theo nếp cũ (truyền thống) và biến đổi cho phù hợp với hoàn cảnh mới.

\section{REFERENCES}

[1] Truong Thi Quoc Anh (2015), Cultural life of residents of Hon Tre island, Nha Trang city, Khanh Hoa province, Master thesis of Culture, University of Social Sciences and Humanities (Vietnam National University, Ho Chi Minh City).

[2] Nguyen Duy Bac (2008), The changes of cultural values in building a market economy in Vietnam today, Encyclopedia Publishing House and Institute of Culture, Hanoi.

[3] Tran Viet Kinh 2004, Bich Dam Island Village, Printed in Ancient Village in Nha Trang. Khanh Hoa Art and Literature Publishing House, p.170-173.

[4] Le Hong Ly (2002), "Some coastal folklore features in the market economy", Journal of Folklore, No. 3 (81), p.38-49.

[5] Ngo Duc Thinh (2000), Folklore of coastal residents, Social Science Publishing House, Hanoi.

[6] Nguyen Thi Hai Yen (2002), Socio-economic assessment in Hon Mun conservation area. Exprimental project of Hon Mun marine protected area, Publishing House of Nha Trang Institute of Oceanography.

[7] Inglehart, Ronald and Wayne E.Baker (2000), "Modernization, Cultural Change and Persistence of Traditinonal Values"American Sociological Review, Vol.65, No.1.

[8] Bronislaw Malinowski (1992), Magic, Science and Religion, Waveland Press, Illinois: 87.

[9] Spindler, Louise S. (1977), Culture change and Modernization: Mini-models and Case Studies New York, Holt, Rinehart and Winston.

\section{CHANGES IN THE BELIEFS OF RESIDENTS ON HON TRE ISLAND, NHA TRANG CITY}

\section{Article info}

Recieved:

22/6/2020

Accepted:

20/9/2020

Keywords: Change of beliefs, change in culture, beliefs

\begin{abstract}
The article mentions the status of beliefs of residents on Hon Tre island with its changes in the current context. On that basis, we will clarify the changes in beliefs; practice of beliefs; gods, places of worship and offerings of worship. At the end of the report are some conclusions about the process of changing beliefs of the residents on Hon Tre island, besides, it pointed out the parallel existence of two movement trends of beliefs, that is to keep the beliefs according to the old (traditional) way and change to suit the new situation.
\end{abstract}

